\title{
Monoterpenoids Induce Agonist-Specific Desensitization of Transient Receptor Potential Vanilloid-3 ion Channels
}

\author{
Muhammad Azhar Sherkheli ${ }^{1,2,3^{*}}$, Heike Benecke ${ }^{1}$, Julia Franca Doerner ${ }^{1}$, Olaf Kletke ${ }^{1}$, A.K. Vogt- \\ Eisele $^{1}$, Guenter Gisselmann ${ }^{1}$ and Hanns Hatt ${ }^{1}$
}

1. Department of Cell Physiology, Ruhr-University-Bochum, Bochum 44801, Germany.2. IMPRS-CB c/o MPI for Molecular Physiology, Otto-Hahn Str. 11, Dortmund, Germany. 3. Research Excellence School, Ruhr-University Bochum, 44801, Bochum, Germany

Received January 15, 2009; Revised March 18, 2009; Accepted April 17, 2009; Published April 19, 2009

\begin{abstract}
Purpose. Transient receptor potential vanilloid-3 (TRPV3) is a thermo-sensitive ion channel expressed in skin keratinocytes and in a variety of neural cells. It is activated by warmth as well as monoterpenoids including camphor, menthol, dihydrocarveol and 1,8-cineol. TRPV3 is described as a putative nociceptor and previous studies revealed sensitization of the channel during repeated short-term stimulation with different agonists. Methods. TRPV3 was transiently expressed in either Xenopus oocytes or HEK293 cells. Whole-cell voltage-clamp techniques were used to characterize the behavior of TRPV3 when challenged with different agonists. Similarly, a human keratinocyte-derived cell line (HaCaT cells) was used to monitor the behavior of native TRPV3 when challenged with different agonists. Results. We report here that prolonged exposure (5-15 minutes) of monoterpenoids results in agonist-specific desensitization of TRPV3. Long-term exposure to camphor and 1,8-cineol elicits desensitizing currents in TRPV3 expressing oocytes, whereas the non-terpenoid agonist 2-APB induces sustained currents. Agonist-specific desensitization of endogenous TRPV 3 was also found in HaCaT cells, which may be taken as a representative for the native system. Terpenoids have a long history of use in therapeutics, pharmaceuticals and cosmetics but knowledge about underpinning molecular mechanisms is incomplete. Our finding on agonist-induced desensitization of TRPV3 by some monoterpenoids displays a novel mechanism through which TRP channels could be functionally modulated. Conclusion. Desensitization of TRPV3 channels might be the molecular basis of action for some of the medicinal properties of camphor and 1,8-cineol.
\end{abstract}

\section{INTRODUCTION}

Thermo-sensitive transient receptor potential (Thermo-TRPs) cation channels are a subgroup of the transient receptor potential (TRP) superfamily of ion channels. They are understood to play a critical role in transduction of thermal and nociceptive information to the central nervous system (1). Transient receptor potential vanilloid3 (TRPV3) is a member of thermo-TRPs, and a structural homologue of transient receptor potential vanilloid-1 (TRPV1). It is heat-sensitive but capsaicin-insensitive (2). TRPV3 is predominantly expressed in rodent and human keratinocytes $(3,4)$. In humans it is co-expressed with TRPV1 in skin, tongue, dorsal root ganglion, trigeminal ganglion, spinal cord and brain $(2,5)$. TRPV3 is implicated in skin sensitization and hyperalgesia in inflamed tissues $(6,7)$ and shows increased expression in the case of peripheral nerve injury (8). Presumably, TRPV3 forms heteromultimeric complexes with TRPV1 (2) and TRPV2 (9). TRPV3 sensitizes to repeated stimuli in heterologous expression systems (HEK293 cells) and in keratinocytes $(4,10,11)$. The proposed mechanism underlying sensitization depends on $\mathrm{Ca}^{2+}$, which is believed to have inhibitory effects on TRPV3 $(11,12)$. Upon repeated stimulation of the channel $\mathrm{Ca}^{2+}$-induced inhibition is abrogated through a yet unknown mechanism. This dis-inhibition of $\mathrm{Ca}^{2+}$ inhibition results in increased amplitudes of evoked currents $(11,12)$. In contrast, $\mathrm{Hu}$ and colleagues (7) described that TRPV3 expressed heterologously in Xenopus oocytes does not show any sensitization upon repeated short-term exposure to the same agonist.

Corresponding Author: Dr. M. Azhar Sherkheli, Department of Cell Physiology, ND 4/164, Ruhr-UniversityBochum, University Street 150, Bochum 44801, Germany; E-Mail: Azhar.Sherkheli@daad-alumni.de 
Desensitization or sensitization of stimulus-induced signals by ion channels and or receptors is a fundamental mechanism used by neuronal systems to adopt to chemical stimuli (13). For example, tryptase released from mast cells acts on airway smooth muscles, leading to homologous beta-adrenergic desensitization thus regulating adrenergic function in smooth muscle cells (14). Similarly, agonists of TRPV1 are known to induce lasting analgesic effects as a result of desensitization of these channels after initial activation $(15,16)$. One such example is methylsalicylate, an analgesic substance from natural sources. Methylsalicylate activates and rapidly desensitizes TRPV1 (17). TRPV1 is known to exhibit two types of pharmacological desensitization events to capsaicin in either neurons or in heterologous expression systems. These desensitization events are classified as acute desensitization (diminished response during constant capsaicin exposure) or tachyphylaxis (attenuated responses to successive applications of capsaicin) $(15,16,18)$. Similarly, cannabinoids modulate TRPV1 activation by altering receptor phosphorylation via the calcium-dependent phosphatase calcineurin (19). As another example, desensitization of the $\mathrm{Ca}^{2+}$-activated TRPM4 channel is reported to be mediated by depletion of phosphatidylinositol-4,5bisphosphate, which is triggered by an elevation in intracellular $\mathrm{Ca}^{2+}$ (20). Furthermore, phosphorylation-based desensitization of TRPM8 and TRPC5 was shown to be a result of $\mathrm{Ca}^{2+}$ evoked activation of protein kinase C. All of these cellular pathways share a dependency on changes in extra- or intracellular $\mathrm{Ca}^{2+}$-concentrations.

Natural products like camphor, menthol, 1,8-cineol and their structural analogues are commonly used as topical analgesics in medicines $(10,21-26)$ and have a broad range of application in therapeutics from anti-inflammatory, antipruritic $(27,28)$ to psychoactive actions (29-31). Several of these natural compounds have been shown to activate TRPV3 $(10,26,32)$. In addition, natural products have played a key role in ligand characterization of TRP ion channels in general $(33,34)$. The function of TRPV3 channels as a target for camphor was studied using shortterm (10-20 seconds) pulses of agonists (10). In the present investigation, however, we aimed to examine TRPV3 activity during prolonged (5-15 minutes) incubation with monoterpenoids, and to moreover compared effects of structurally distinct groups of compounds. We observed $\mathrm{Ca}^{2+}$ independent desensitization of TRPV 3 channels during prolonged incubation with camphor, 1,8cineol, menthol, and dihydrocarveol, but not with the synthetic agonist 2-APB. Our findings present a mechanism of desensitization for TRPV3, which is agonist- and time-dependent, but independent of extracellular $\mathrm{Ca}^{2+}$. These differences are likely the result of different binding domains and activation mechanisms for different classes of TRPV3 ligands.

\section{MATERIALS AND METHODS}

\section{Expression vectors for TRP channels}

The mouse TRPV3 was a generous gift from D. Julius (UCSF, CA, USA). For efficient expression in Xenopus oocytes, cDNA was subcloned by a PCR-based standard method into the oocyte expression vector pSGEM (35).

\section{Synthesis and injection of TRP cRNA}

The generation of cRNA was performed by standard methods as described elsewhere (21). In brief, plasmids containing cloned cDNA were linearized downstream of the end of the cDNA. Capped RNA was synthesized in the presence of capping analogue $\mathrm{m}^{7} \mathrm{G}\left(5^{\prime}\right) \mathrm{ppp}\left(5^{\prime}\right) \mathrm{G}$ using the AmpliCap-T7 MessageMaker Kit (Epicentre, Madison, WI). cRNA was ethanol-precipitated and re-dissolved in RNase-free water to give a final concentration of $1 \mu \mathrm{g} / \mu \mathrm{l}$. Ovarian lobes were obtained from mature female Xenopus laevis frogs. The frog was anaesthetized by immersion in $0.15 \% 3$-aminobenzoic acid ethyl ester and a partial ovarectomy was performed to isolate oocytes. Oocytes were rinsed in $\mathrm{Ca}^{2+}$-free modified Barth's solution $(88 \mathrm{mM} \mathrm{NaCl}, 1 \mathrm{mM}$ $\mathrm{KCl}, 2.4 \mathrm{mM} \mathrm{NaHCO}, 5 \mathrm{mM}$ Tris- $\mathrm{HCl}, 0.82 \mathrm{mM}$ $\mathrm{MgSO}_{4}$, and $100 \mathrm{U} / \mathrm{ml}$ penicillin, $50 \mu \mathrm{g} / \mathrm{ml}$ streptomycin at $\mathrm{pH}$ 7.4). After treatment of the ovarian tissue with collagenase [Type I (Sigma, St. Louis, MO), $4 \mathrm{mg} / \mathrm{ml}$ in $\mathrm{Ca}^{2+}$-free Barth's solution] for two hours at room temperature, the oocytes were incubated overnight in fresh Barth's solution $\left(15^{\circ} \mathrm{C}\right)$. After $24 \mathrm{~h}$, mature healthy oocytes (stage $\mathrm{V}$ to $\mathrm{VI}$ ) were selected for cytoplasmic injection of cRNA (about 50 nanoliter per oocyte; approximate cRNA concentration $1 \mu \mathrm{g} / \mu \mathrm{l})$ with a sharp pipette using a pulsed injector driven by air pressure (npi PDES 04T, Tamm, Germany). Afterwards, injected oocytes were placed in ND-96 solution $(96 \mathrm{mM} \mathrm{NaCl}, 2$ $\mathrm{mM} \mathrm{KCl}, 1.8 \mathrm{mM} \mathrm{CaCl} 2,1 \mathrm{mM} \mathrm{MgCl}_{2}, 5 \mathrm{mM}$ HEPES, 100 units $/ \mathrm{ml}$ penicillin $\mathrm{G}, 50 \mu \mathrm{g} / \mathrm{ml}$ 
streptomycin sulphate and $25 \mu \mathrm{g} / \mathrm{ml}$ amphotericin $\mathrm{B} ; \mathrm{pH} 7.4)$ and incubated at $16-18^{\circ} \mathrm{C}$. Oocytes were tested for functional expression of TRP channels after 3 to 5 days (at room temperature $\left.23^{\circ} \mathrm{C}\right)$.

\section{Electrophysiological recordings in oocytes}

Two-electrode voltage-clamp recordings were used to obtain current responses to applied substances. Drugs were diluted to the final concentration in $\mathrm{Ca}^{2+}$-free $(100 \mathrm{mM} \mathrm{NaCl}, 2.5$ $\mathrm{mM} \mathrm{KCl}, 10 \mathrm{mM}$ HEPES, $200 \mu \mathrm{M}$ flufenamic acid 10 mM EGTA: $\mathrm{pH}$ 7.4) standard extracellular solution (SES). Agonists were applied by means of a multibarrel single tip superfusion device or by manual application. Stimulus duration was usually 10-20 sec and 5, 10 or 15 minutes for desensitization experiments. Electrodes were pulled from borosilicate glass using a Kopf vertical pipette puller and backfilled with $3 \mathrm{M} \mathrm{KCl}$. Oocytes were constantly held at $60 \mathrm{mV}$ using a command from the amplifier and evoked current signals were acquired using the PCLAMP software (Axon Instruments, Sunnyvale, CA) and recorded with a twoelectrode voltage-clamp amplifier (TURBO TEC03, npi, Tamm, Germany).

\section{Cell culture and transfection of HEK293 cells}

TRPV3 cloned into pCDNA3.1 vector was used to transfect HEK293 cells. HEK293 cells were maintained at standard conditions in a minimum essential medium supplemented with $10 \%$ fetal bovine serum, 100 units $/ \mathrm{ml}$ penicillin and streptomycin, and $2 \mathrm{mM}$ L-glutamine. Semi confluent cells were transfected in $35 \mathrm{~mm}$ dishes (Becton Dickinson, Heidelberg, Germany) using the $\mathrm{Ca}^{2+}$-phosphate-precipitation technique as described previously (36). Measurements were performed 24-48 hours after transfection.

\section{Electrophysiology in HEK293 cells}

Recordings were performed using the whole-cell mode of the patch-clamp technique. Cells were maintained in an extracellular recording solution containing $140 \mathrm{mM} \mathrm{NaCl}, 5 \mathrm{mM} \mathrm{KCl}, 1 \mathrm{mM}$ $\mathrm{MgCl}_{2}, 10 \mathrm{mM}$ HEPES, $5 \mathrm{mM}$ EGTA, $\mathrm{pH}$ 7.4. Patch electrodes were pulled from borosilicate glass (1.2 mm O.D. x $1.17 \mathrm{~mm}$ I.D., Harvard apparatus, Edenbridge, Kent, UK) and fire polished to 4-6 $\mathrm{M} \Omega$ tip resistance using a horizontal pipette puller (Zeitz Instr., Munich,
Germany). The pipette solution contained 140 $\mathrm{mM} \mathrm{KCl}, 1 \mathrm{mM} \mathrm{MgCl} 2,0.1 \mathrm{mM} \mathrm{CaCl} 2,5 \mathrm{mM}$ EGTA, 10 mM HEPES, pH 7.3 for recordings.

\section{Cell culture and calcium imaging studies in HaCaT cells}

Cell culture methods: $\mathrm{HaCaT}$ cells were cultured at $37^{\circ} \mathrm{C}\left(5 \% \mathrm{CO}_{2}\right.$ and $95 \%$ humidified air $)$ in Dulbecco's Modified Eagle Medium (DMEM) containing $10 \%$ FBS and $1 \%$ penicillin/ streptomycin. Cells were grown to a confluency of no more than $70 \%$ and splitted using Trypsin/EDTA.

Detection of TRPV3 in HaCaT cells: As previously reported, TRPV3 immunoreactivity is present in HaCaT cells (37). We confirmed the expression of TRPV3 in HaCaT cells at mRNA level by RT-PCR and PCR product was verified by sequencing. Cells were trypsinized as described above and harvested by centrifugation. Total RNA was isolated using the RNAeasy Mini Kit (QIAgen) according to the manufacturer's instruction. cDNA synthesis was performed with $1 \mu \mathrm{g}$ of total RNA using the iSCRIPT cDNASynthesis Kit (BIORAD) according to the supplier's protocol. For PCR amplification, the cDNA was subjected to a standard PCR reaction involving hTRPV3 specific intron-spanning primers (hTRPV3_fw: ctgggcgaacatgctctact; and hTRPV3_rw: ttcagacacccactgagcac), followed by analysis of the PCR product by agarose gel electrophoresis (1\%). To estimate the right product size $(856 \mathrm{bp})$ a $1 \mathrm{~kb}$ size standard marker (Fermentas) was used.

Single cell calcium imaging: $\mathrm{HaCaT}$ cells grown in $35 \mathrm{~mm}$ dishes were incubated for $30 \mathrm{~min}$ at $37^{\circ} \mathrm{C}$ with loading buffer containing Ringer solution ( $140 \mathrm{mM} \mathrm{NaCl}, 5 \mathrm{mM} \mathrm{KCl}, 2 \mathrm{mM} \mathrm{CaCl}_{2}$, $1 \mathrm{mM} \mathrm{MgCl}, 10 \mathrm{mM}$ HEPES; $\mathrm{pH}$ 7.3) and $3 \mu \mathrm{M}$ Fura-2-AM (Molecular Probes). Calcium imaging was performed using the multiway wavelength illumination system POLYCHROME II (T.I.L.L Photonics GmbH, Planegg, Germany) for excitation. Changes in cytosolic $\mathrm{Ca}^{2+}$ concentrations were analyzed using a PCO interline chip camera. Acquisition and calculation of fluorescence signals obtained from excitation of the Fura-2 dye at 340 and $380 \mathrm{~nm}$ was done using the T.I.L.L-Vision-software. For stimulation experiments camphor and 2-APB were diluted in Ringer solution to a final concentration of $6 \mathrm{mM}$. Cells were subjected to 
short-term (10 seconds) and long-term stimulation (3-4 minutes) at the indicated time points. For data analysis relative amplitudes of related stimulus-induced $\mathrm{Ca}^{2+}$-signals post long-term stimulation were averaged and compared to the maximal amplitudes obtained with initial shortterm exposure of the same agonist (set as $100 \%$ in Figure $5 \mathrm{c}$ and e).

\section{Reagents}

All cell culture reagents were obtained from GIBCO/Invitrogen (Karlsruhe, Germany). Chemicals for intracellular and extracellular solutions in patch clamp measurements were obtained from Sigma Aldrich, including the following compounds; 1,8-cineole, 2aminoethoxydiphenyl borate (2-APB), camphor and dihydrocarveol. (1R,2S,5R)-(-)-2-Isopropyl5-methylcyclohexanol (referred in the text as menthol) was obtained from Symrise (Holzminden, Germany).

\section{Data Analysis}

All data were analysed for statistical significance by using student's paired-t test (Microsoft Excel). Statistical probability $(p)$ is expressed as $* p<$ $0.05, * * p<0.01$ and $* * * p<0.001$ to indicate various levels of statistical significance. Data are expressed as mean \pm S.E.M. of 6 to 14 independent measurements of responses under similar experimental conditions unless otherwise indicated.

\section{RESULTS}

\section{Desensitization of TRPV3 by monoterpenoids}

To investigate the long-term effects of agonists like camphor, 1,8-cineol, 2-APB, dihydrocarveol and menthol on TRPV3 activity, we performed two-electrode voltage-clamp measurements in Xenopus oocytes expressing TRPV3 while recording in $\mathrm{Ca}^{2+}$-free SES buffered with $10 \mathrm{mM}$ EGTA. For control experiments TRPV3 cRNA injected oocytes were exposed to either $1 \mathrm{mM} 2$ APB or $10 \mathrm{mM}$ camphor. Both compounds elicited robust currents which were blocked by ruthenium red (RR) a general blocker of TRPV channels (Figure 1a). The corresponding mockinjected (either the empty vector or normal saline) oocytes did not respond to 2-APB or camphor challenge (Figure 1b). For potential desensitization experiments, a short-term exposure (10-20 seconds) to the agonist was carried out to record the response of TRPV3 channels. Acute desensitization was examined by 10-minute incubation with the same or different agonists followed by 3-5 minutes washout with $\mathrm{Ca}^{2+}$-free SES. To monitor tachyphylaxis a second short-term stimulus with the desired agonist was applied. TRPV3 expressing Xenopus oocytes showed strong inward currents at a holding potential of $-60 \mathrm{mV}$ when challenged with $3 \mathrm{mM}$ 2-APB [EC ${ }_{50} \sim 500 \mu \mathrm{M}$ in oocytes (26)]. Currents quickly reached steady state and did not significantly change $(20 \pm 6 \%$ increase; $p<0.42$; $\mathrm{n}=6$ ) in continuous presence of $3 \mathrm{mM} 2-\mathrm{APB}$ over a period of 10 minutes. Steady state currents reversed back to baseline after washout with $\mathrm{Ca}^{2+}$ free SES. A following short-term application of 2APB evoked currents of significantly higher magnitude compared to the initial short-term response (Figure 2a,d). In addition, long-term incubation with 2-APB also significantly increased the second camphor response $(77 \pm 12 \%$, $\mathrm{p}=0.0002, \mathrm{n}=6$, Figure 2a).

Next, we asked whether the response to 2APB is affected by preceding long-term incubation (10 $\mathrm{min})$ with monoterpenoids like camphor (10 mM), 1,8-cineol $(10 \mathrm{mM})$, menthol $(10 \mathrm{mM})$ or dihydrocarveol $(10 \mathrm{mM})$, respectively. Camphor is typically used in topical applications at concentrations about $10-15 \%$ ( 300 - $600 \mathrm{mM})$. Previous studies (10) employed $10 \mathrm{mM}$ camphor as standard reference dose for TRPV3 activation in HEK293 cells. It is important to note that higher concentrations of camphor are difficult to dissolve in aqueous solutions. In oocytes an $\mathrm{EC}_{50}$ of $6 \mathrm{mM}$ was established (26). Thus, we used $10 \mathrm{mM}$ as standard dose to study the effects of monoterpenoids on TRPV3 during long-term application. Using a similar protocol as mentioned above, elicited currents induced by short-term application of $3 \mathrm{mM} 2$-APB were measured before and after long-term incubation with monoterpenoids. 2-APB evoked significantly larger TRPV3 mediated currents when previously incubated with camphor ( $36 \pm 4 \%$; Figure $2 b, d, f)$, menthol (38 $5 \%$; Figure 2d, Figure 3a, c), dihydrocarveol ( $35 \pm 2 \%$; Figure $2 d$, Figure $3 \mathrm{~b} \&$ d) or 1,8-cineol $(31.4 \pm 6 \%$; Figure $2 \mathrm{c} \& \mathrm{~d})$, respectively. 


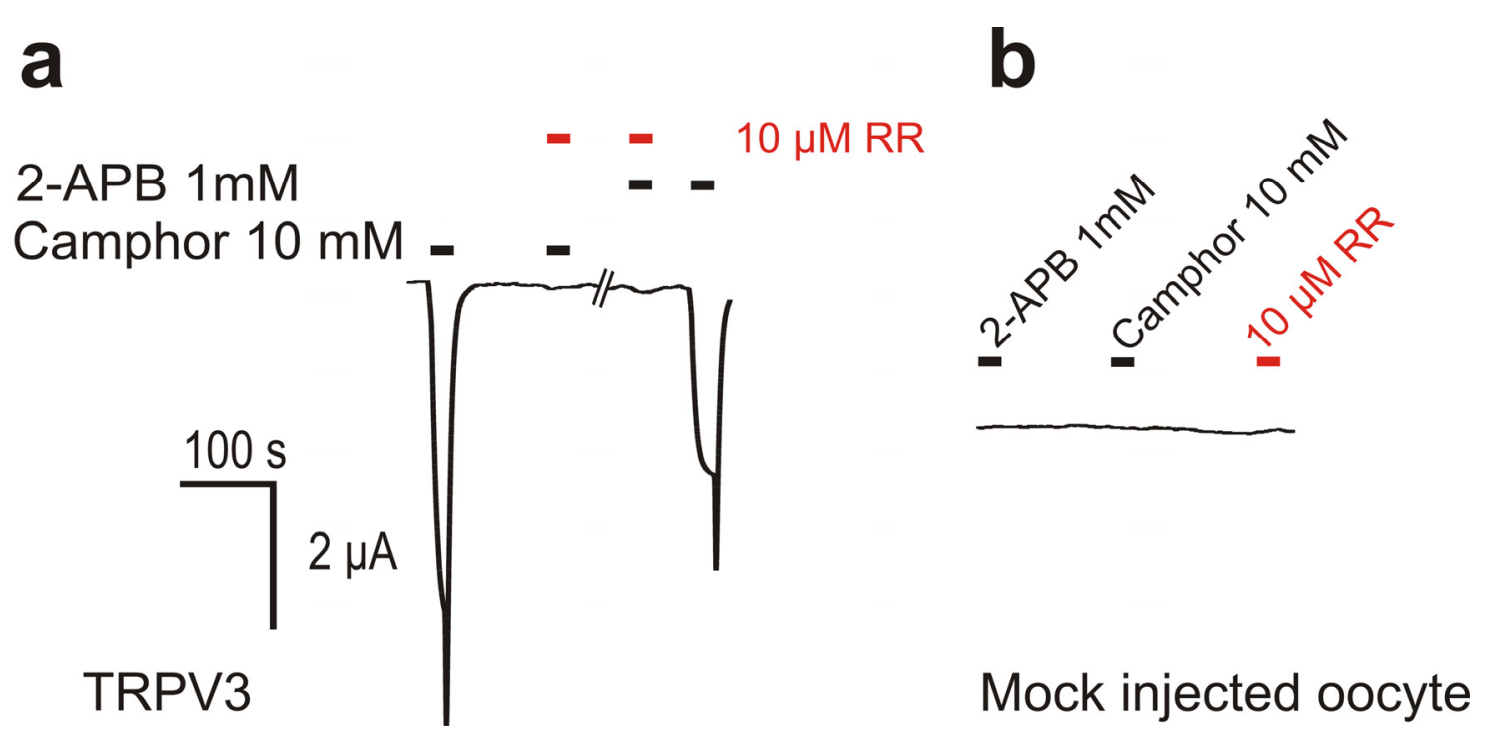

Figure 1. (a) Representative trace showing recombinant TRPV3 responses in oocytes to standard agonists and block by RR (ruthenium red). (b) Representative trace of mock injected oocytes.

In contrast to 2-APB, a second short-term reapplication of camphor after prolonged incubation with $10 \mathrm{mM}$ camphor resulted in a drastic reduction $(96.8 \pm 2 \%$ decrease; $\mathrm{p}<0.0008$; $\mathrm{n}=6$ ) of the response (Figure $2 b$, e \& f), demonstrating tachyphylaxis to the camphor response. In addition, acute desensitization to camphor could be observed during long-term application of the substance (Figure 2b, e \& f). Similar effects were observed for other monoterpenoids. A second short-term application resulted in reduced currents after long-term application of the desired monoterpenoid compared to the initial short-term response (10 $\mathrm{mM}$ 1,8-cineol: $63 \pm 4 \%$ decrease, $\mathrm{p}<0.001, \mathrm{n}=6$; Figure 2c \& e; $10 \mathrm{mM}$ dihydrocarveol: $80 \pm 6 \%$ decrease, $n=7, p<0.00005$; Figure $3 \mathrm{~b} \& \mathrm{~d}$ and 10 $\mathrm{mM}$ menthol: $65 \pm 6 \%$ decrease, $\mathrm{n}=6, \mathrm{p}<0.0004$; Fig $3 \mathrm{a} \& \mathrm{c}$ ). Acute desensitization was also observed for the bicyclic monoterpenoid 1,8cineol (Figure 2c), but is less pronounced for menthol (Figure 3 a \& c) or appears only after 15minutes incubation for the monocyclic monoterpenoid dihydrocarveol (Figure $3 \mathrm{~b} \& \mathrm{~d}$ ). To analyze the recovery time of TRPV3 from camphor-induced desensitization, prolonged washout ( $\sim 40$ minutes) with $\mathrm{Ca}^{2+}$-free SES was carried out with intermittent application of 2APB. TRPV3 responses to camphor virtually returned to initial magnitudes after about 40minutes washout with $\mathrm{Ca}^{2+}$-free SES (Figure 2f).

\section{TRPV3 desensitization in HEK293 cells}

To further test whether the observed desensitization is independent of the expression system, we expressed TRPV3 in HEK293 cells. Whole cell currents were measured using the patch-clamp technique. Camphor and 2-APB challenges were presented to HEK293 cells expressing TRPV3. Consistent with the results obtained in Xenopus oocytes, acute desensitization was observed in the presence of camphor, whereas 2-APB elicited a sustained response over a period of $5 \min$ (Figure 4, $\mathrm{n}=3$ ). At lower doses of camphor $(6 \mathrm{mM})$ the onset of desensitization in HEK293 cells was not as pronounced (data not shown) as it was with 10 mM camphor.

\section{TRPV3 desensitization in HaCaT cells}

To investigate whether endogenous TRPV3 channels show desensitization upon long-term exposure to camphor, we performed experiments with the keratinocytes-derived $\mathrm{HaCaT}$ cell line. The expression of TRPV3 in HaCaT cells was confirmed at mRNA level by RT-PCR (Figure 5a) and by sequence analysis of the PCR-product. The reactivity of keratinocytes to camphor and 2APB was previously described as a change of intracellular calcium levels (3). We focused on camphor as a representative prototypical monoterpenoid inducing desensitization and compared its effects to 2-APB. 

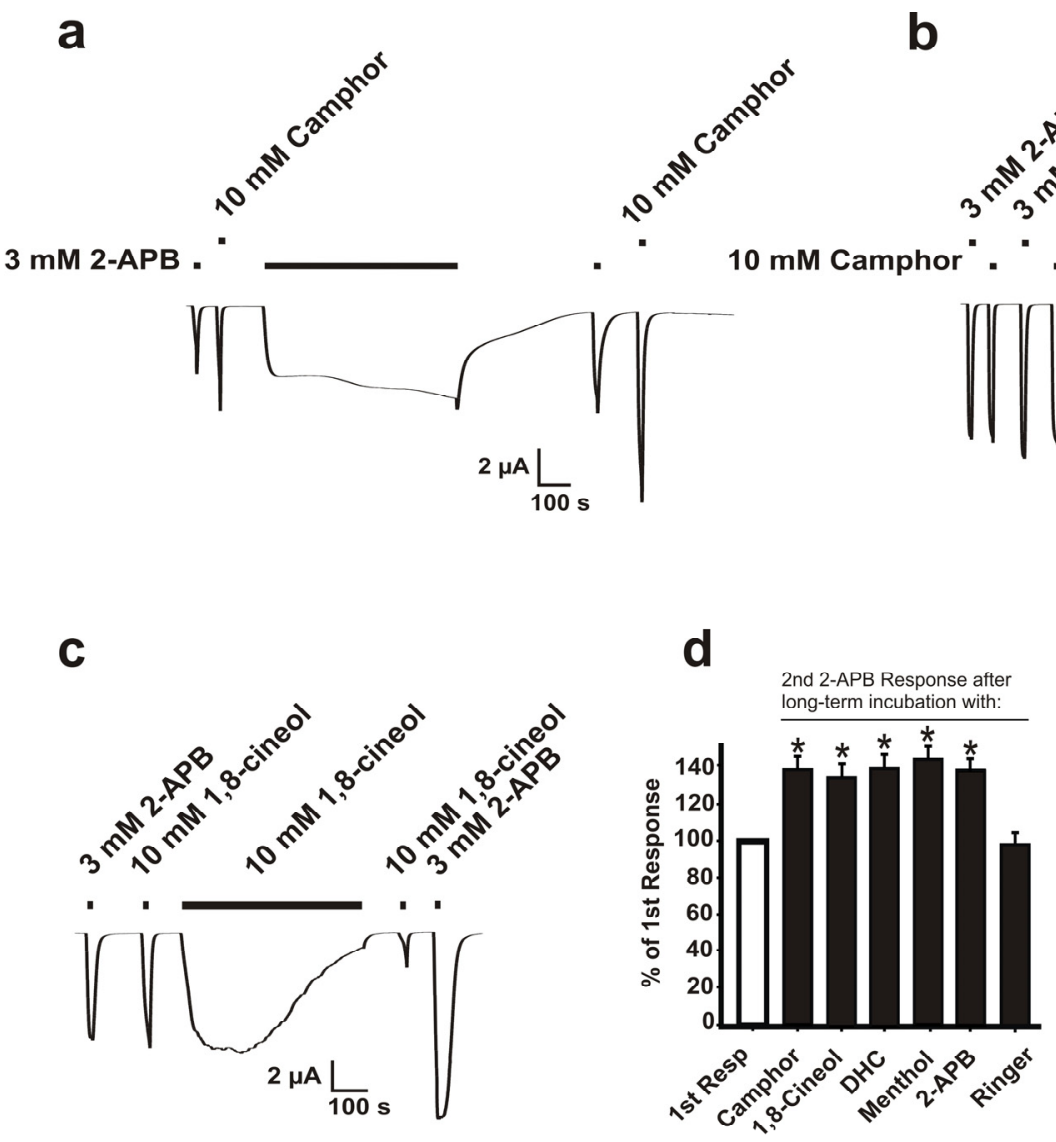

e
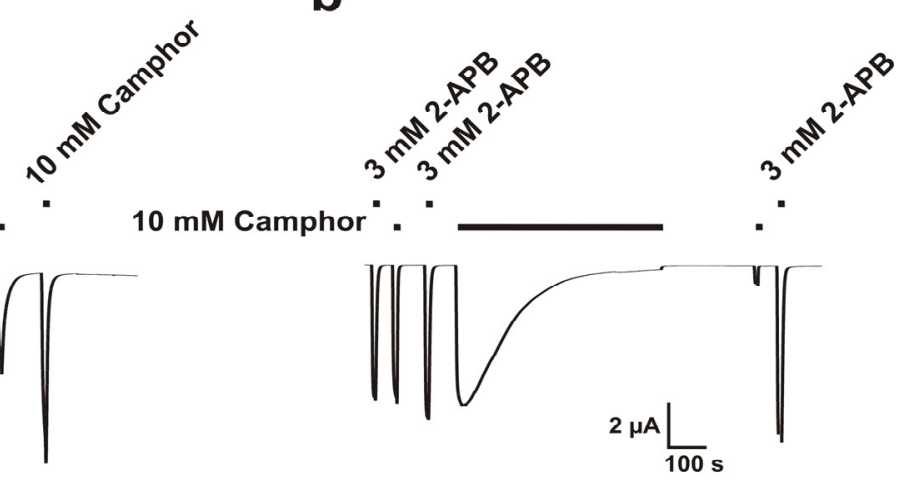

C

\section{f}

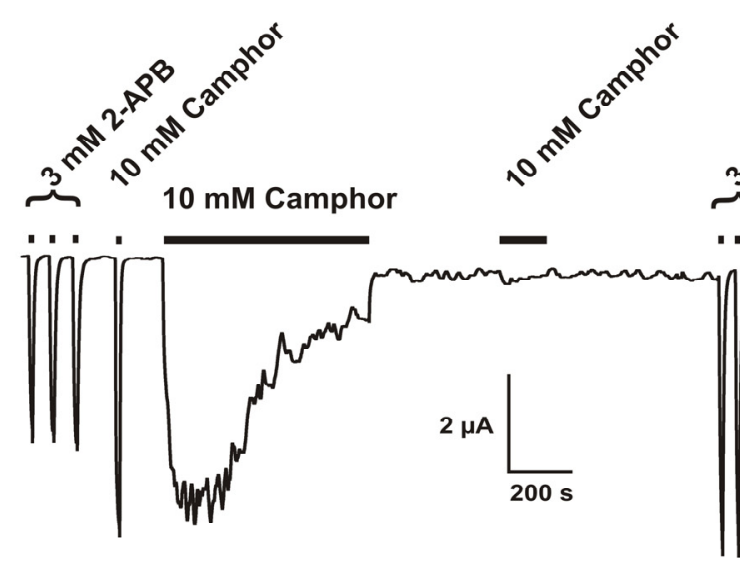

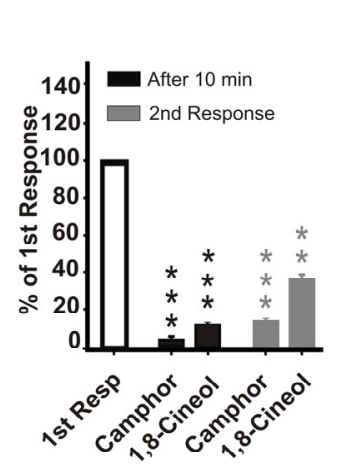

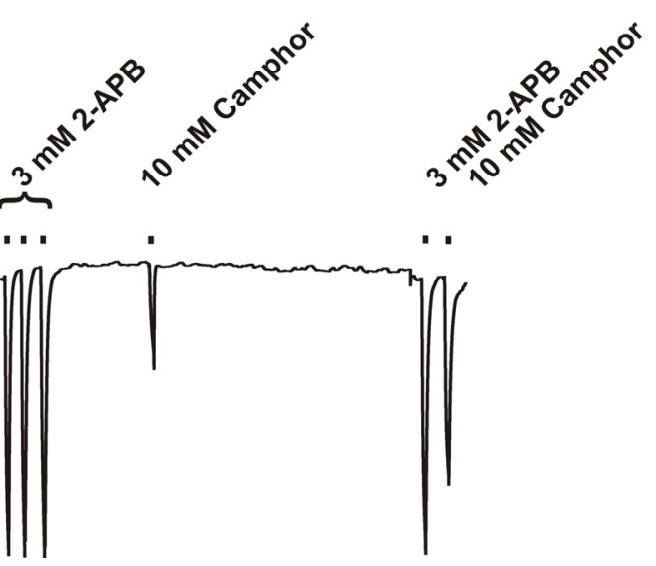

Figure 2. Desensitization of TRPV3 by camphor \& 1,8-cineole. (a) 2-APB, (b) camphor and (c) 1,8-cineol were applied for 10-20 sec (short term) or 10 minutes (long-term). The bar diagram (d) shows quantified data for the relation of the 1st and 2nd short-term exposure of the respective agonists after long-term exposure to 2-APB or monoterpenoids. Data are expressed as mean \pm SEM $(n=6)$. (e) quantification of desensitization events observed with camphor and 1,8-cineole. (f) original trace showing desensitization to camphor and then recovery of TRPV3 after long-term washout with $\mathrm{Ca}^{2+}$-free SES. 

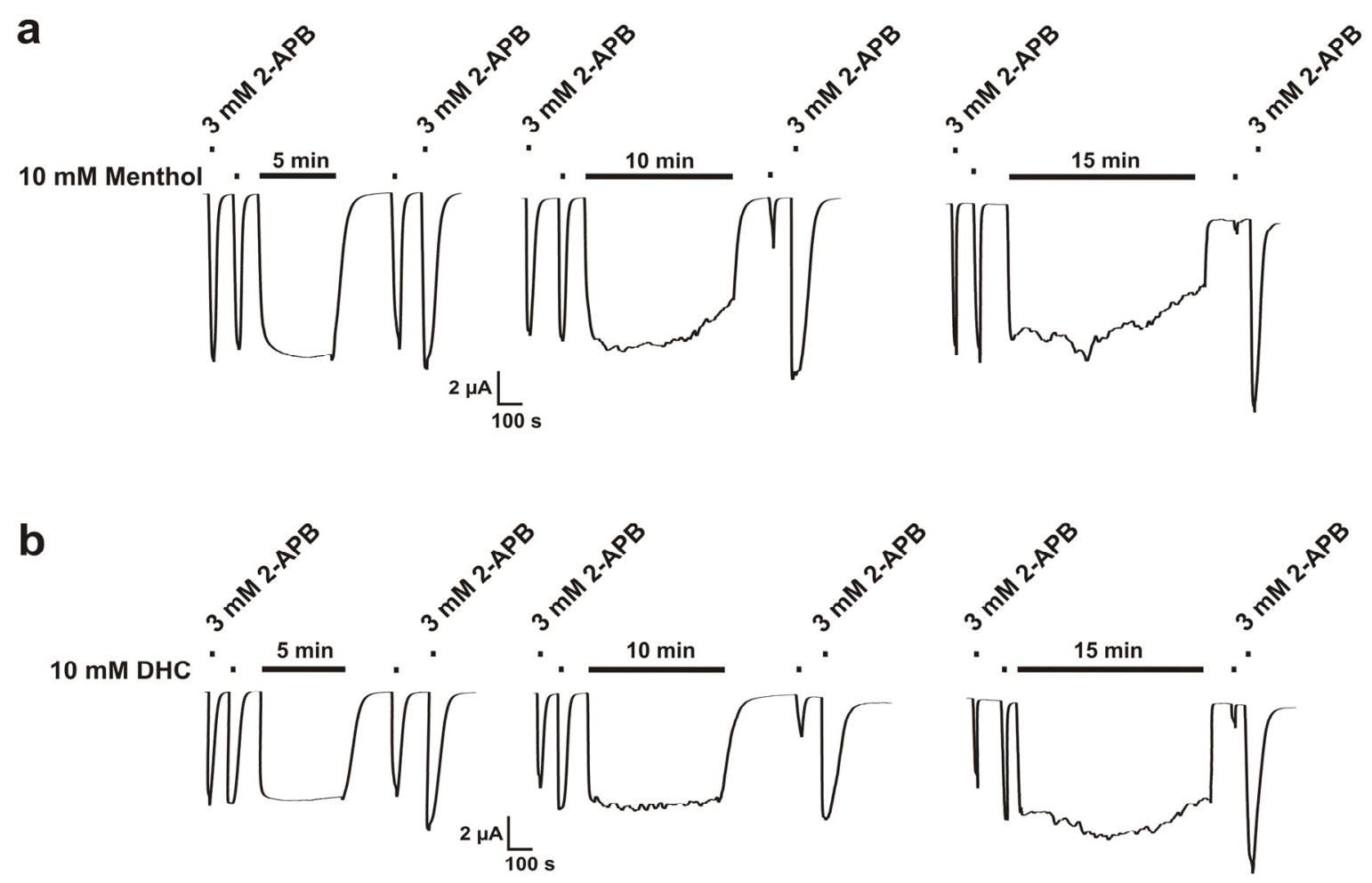

C
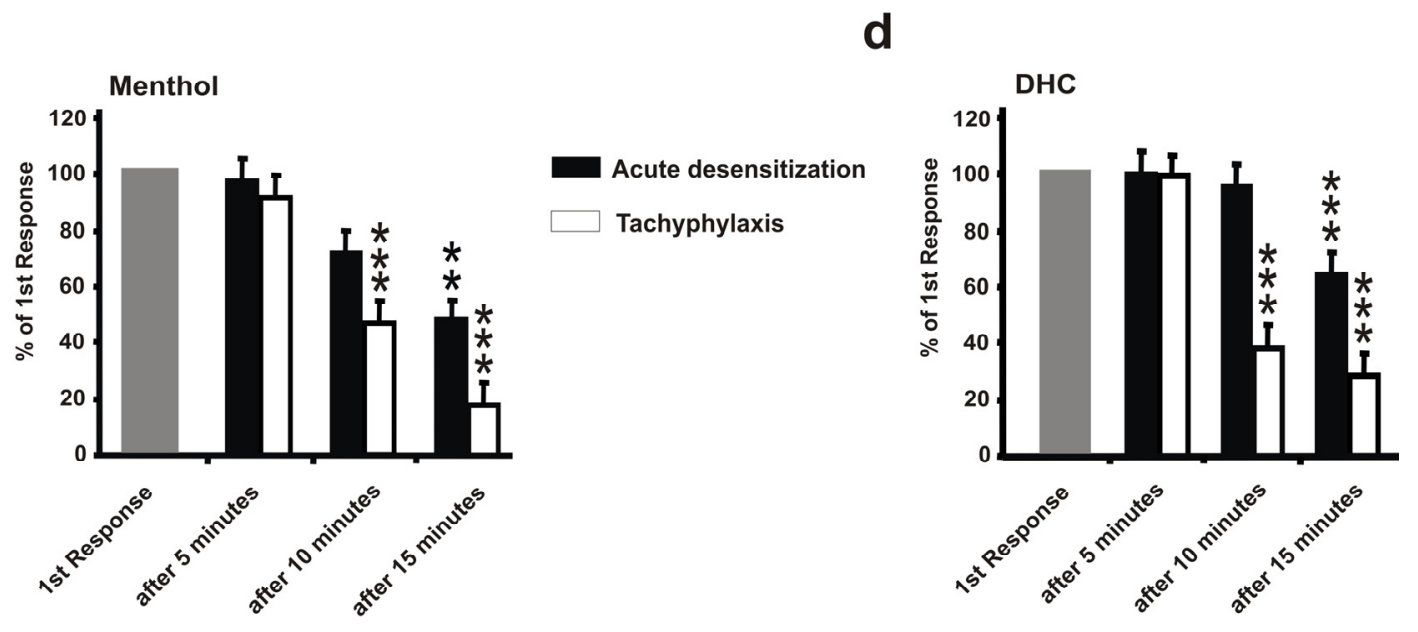

Figure 3. Desensitization of TRPV3 by monocyclic monoterpenoids. Menthol (a) and DHC (b) were applied for 10-20 s (short term) or 5, 10 and 15 minutes (long-term) exposure to explore possible agonist and timedependent acute desensitization or tachyphylaxis. The bar diagrams (c \& d) show the relationship of the 1st and 2nd short-term exposure of menthol (a) or DHC (b) after long-term exposure. Data is expressed as mean $\pm \operatorname{SEM}(n=6)$.

Initially, HaCaT cells were analyzed with respect to repetitive stimulation by either $6 \mathrm{mM}$ camphor or $300 \mu \mathrm{M} 2$-APB applied for 10 seconds (shortterm application) with 40-50 seconds interstimulus intervals as indicated (Figure 5). In both cases the same cells responded repeatedly to either substance. However, in the case of 2-APB the amplitudes of successive $\mathrm{Ca}^{2+}$-signals did not vary significantly $(\mathrm{p}>0.19 ; \mathrm{n}=44$ cells $)$ whereas the camphor-induced $\mathrm{Ca}^{2+}$-signal reached its maximum amplitude after the second to third application (sensitization effect, see Figure 5 b \& d). 
a

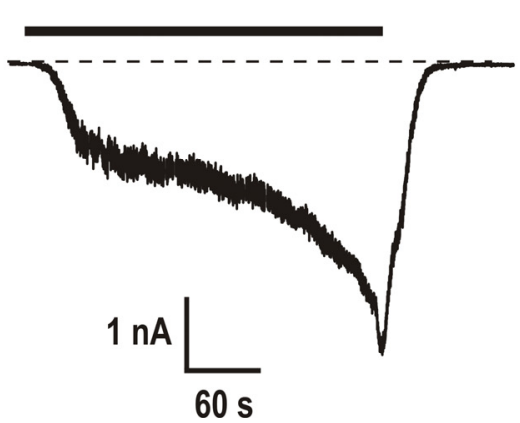

b

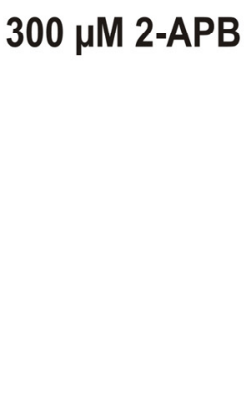

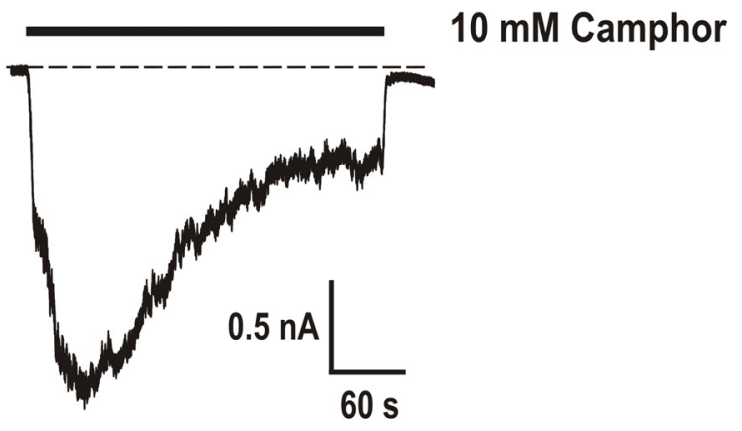

Figure 4. Representative tracing showing TRPV3 mediated currents in HEK293 cells as evoked by standard agonists. (a) 2-APB induced non-desensitizing TRPV3 mediated currents (b) whereas camphor induced desensitization of TRPV 3 mediated currents . Experiments were performed at $-60 \mathrm{mV}$ holding potential under calcium free extracellular environments.

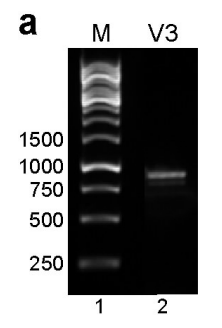

b

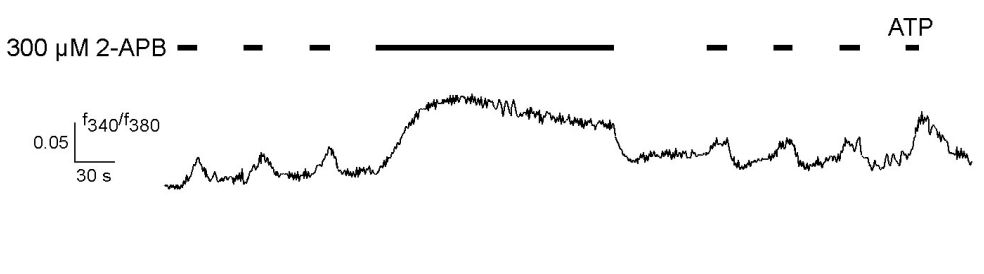

d

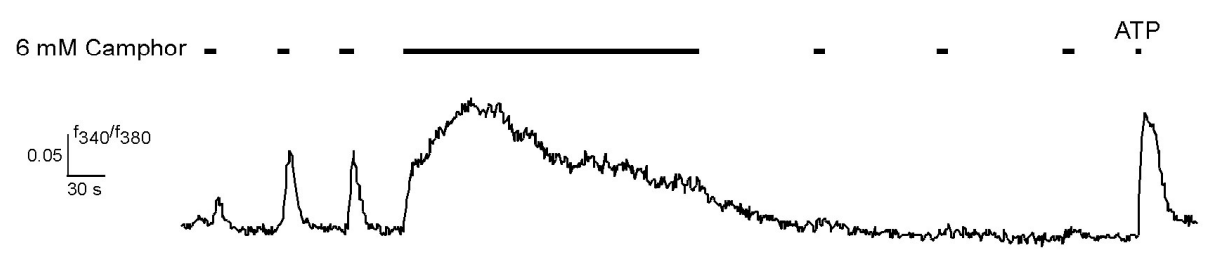

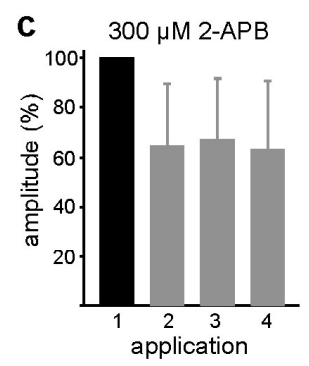

e

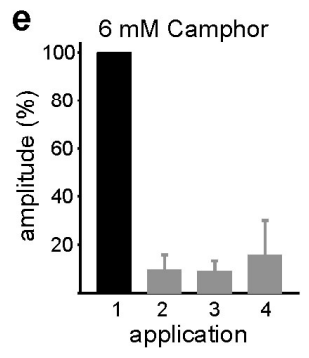

Figure 5. Effects of 2-APB and camphor on HaCaT cells TRPV3.

(a) RT-PCR detection of TRPV3 mRNA in HaCaT cells. The PCR product was analyzed by agarose gel electrophoresis (lane 1: $1 \mathrm{~kb}$ size marker and lane $2 \mathrm{hTRPV} 3$ ). Representative ratiofluorimetric recordings of stimulation experiments of Fura-2 loaded HaCat cells with either $300 \mu \mathrm{M}$ 2-APB (b) or $6 \mathrm{mM}$ camphor (d) are shown respectively. Changes of cytosolic $\mathrm{Ca}^{2+}$-levels in response to stimulation are depicted as the fluorescence ratio $\left(\mathrm{f}_{340} / \mathrm{f}_{380 \mathrm{~nm}}\right)$ and displayed as a function of time. HaCaT cells were first stimulated for 10 15 seconds (short-term) followed by long-term exposition (3-4 $\mathrm{min}$ ) to either substance at the indicated timepoints (bars above). After washout of the stimuli for $90 \mathrm{sec}$ with Ringer solution subsequent short-term stimulations were performed as indicated. Figure $5 \mathrm{c} \&$ e are data quantification for tachyphylaxis after longterm application of either 2-APB or camphor. The mean amplitudes of each stimulation post long-term exposition (application 2-4; grey bars) were normalized to the maximal amplitude obtained by pooling together the maximum signal-amplitudes observed before long-term incubation with agonists (set as $100 \%$; black bar). For camphor experiments $\mathrm{p}<0.0001, \mathrm{n}=33$ cells and for 2-APB $\mathrm{p}>0.19, \mathrm{n}=44$ cells. Data pooled from experiments performed on different days. Error bars are representing SD. 
To analyze the effect of long-term exposure, we first performed single stimulations until the maximum amplitude had reached and then applied the respective substance for 3-4 minutes. In the case of 2-APB $\mathrm{Ca}^{2+}$-signals stay high during long-term application (Figure 5b), while camphor responses decline in continuous presence of the agonist (Figure 5d). Contrary to 2-APB, reapplication of camphor subsequent to a washout-interval of $90 \mathrm{sec}$ post long-term stimulation resulted in a drastically lower $\mathrm{Ca}^{2+}$ signal ( $\sim 10 \%$ of the initial signal was observed; $\mathrm{p}<0.0001: \mathrm{n}=33$ cells) as compared to the maximum amplitude obtained at the beginning of the experiment (Figure 5d). These findings are in concert with our results from heterologous systems and hence support the observation of desensitization of TRPV3 induced by specific bicyclic monoterpenoids.

\section{DISCUSSION}

TRP channels are turning out to be important potential targets for novel analgesics (38-40). In addition to that, the analgesic properties of many natural products have been attributed to the modulation of TRP channel activity. TRPV 3 has structurally non-related agonists like monoterpenoids and 2-APB. Thus, we investigated possible differences in the activation mechanisms of TRPV3 by these two diverse classes of ligands.

TRPV3 and TRPV1 exhibit structural homologies and are often co-expressed in a variety of cells $(2,4,5,41-43)$. Initial findings on TRPV3 reported that it exhibits strong sensitization upon repetitive short-term exposure to heat, 2-APB $(4,5,44,45)$ as well as to camphor (10), which is consistent with our results obtained for short-term application of camphor in $\mathrm{HaCaT}$ cells. In the case of terpenoids, sensitization of TRPV3 is surprising, since camphor has been used over centuries as an analgesic, anti-pruritic and soothing substance both in Eastern and Western medicine. In the present investigation we addressed this question by a specially adopted agonist incubation protocol that fits to the time course of long-term topical applications. Instead of exposing TRPV3 to camphor or 2-APB for 10 or 20 seconds we applied either substance alone up to 15 minutes and re-exposed the channels to camphor or 2-APB challenge after washout.

Our data substantiates the observation that camphor and 1,8-cineol stimulation leads to desensitization of TRPV3 channels after preceding long-term application. Beside acute desensitization, we observed a reduction in current amplitude upon second short-term application, typically referred to as tachyphylaxis. A similar finding was observed for 1,8-cineol, whereas menthol and DHC only induced strong tachyphylaxis and very little acute desensitization during long-term application (see Figure 3). 2APB, however, did neither induce acute desensitization nor tachyphylaxis arguing for the existence of an agonist specific mechanism of TRPV3 channels activation. 2-APB and bicyclic monoterpenoids such as camphor or 1,8 cineol may indeed activate TRPV3 through different mechanisms, since point mutations at positions H426 and R696 render the channel insensitive to 2-APB, but not to camphor (46). Further on, citral, a bioactive component of lemongrass, has been reported to both activate and subsequently render TRPV3 channels strongly inactive (47), and this inhibition occurred much faster in the absence of intracellular calcium. Calcium is a known modulator of TRP channels activity and was shown to directly gate TRPA1 $(48,49)$, TRPM4 and TRPM5 (50) and has inhibitory effects on TRPV3 (12). A supra-threshold rise in intracellular calcium concentrations (as a result of calcium influx) is believed to be necessary to produce any tangible degree of acute desensitization or tachyphylaxis of TRP cation channels $(15,51-53)$. Citral and now the class of bicyclic monoterpenoids including camphor and 1,8 cineol apparently share a commonness in that $\mathrm{Ca}^{2+}$ is not essential for agonist-induced desensitization of TRPV3. This argues not only for an agonist-specific and time-dependent but also a $\mathrm{Ca}^{2+}$-independent mechanism of camphorinduced desensitization of TRPV 3 channels.

$\mathrm{HaCaT}$ cells showed also desensitized calcium responses to camphor but not to 2-APB. Although TRPV1 is reported to respond to both camphor and 2-APB, functionality of TRPV1 channels in the HaCat cell line remains controversial $(54,55)$. 2-APB does further activate TRPV2 channels, however the human orthologue is apparently insensitive to 2-APB (56). We therefore conclude that 2-APB and camphor likely activates TRPV 3 channels and not TRPV1 and TRPV2 in HaCat cells. In general, this part of the study clearly indicates that TRPV3 desensitization is significantly manifested by camphor, which is a contrast to that of 2-APB.

We also assumed that different sets of agonists bind to different agonist binding sites or 
domains on TRPV3, thereby allosterically interacting to control the maximal response of TRPV3. Thus we generated mutant TRPV3 channel (data not shown in this paper) which specifically shows differential responses to camphor and 2-APB. This mutant is totally nonresponsive to camphor but sensitivity to $2-\mathrm{APB}$ and DHC is intact. This site-specific interaction may be involved in desensitization seen with some (camphor or 1,8-cineol) but not with other substances (e.g., 2-APB). However, the exact contribution of this point mutation in desensitization of TRPV3 needs further investigation. Additional evidence that camphor and 2-APB act by two different mechanisms is the facts that after prolonged camphor-treatment camphor responses are drastically reduced while 2-APB responses sensitized (see Figure 2). Thus, TRPV3 receptor is both sensitized (by one agonist) and desensitized (by another) at the same time depending on the type of agonist used.

As camphor and 1,8-cineol (25) are known analgesics and share similarities in their chemical structures, it is not surprising that both substances have the same molecular target for their analgesic effect. Desensitization events by menthol and dihydrocarveol reflect the differences in pharmacological effects within the monoterpenoids. While the bicyclic monoterpenoids (camphor or 1,8-cineol) induce both acute desensitization and tachyphylaxis, monocyclic monoterpenoids (dihydrocarveol or menthol) preferentially induce only tachyphylaxis. Based on the distinct desensitization profiles, TRPV 3 agonists can be classified into three classes. The first category consists of non-desensitizing or 2-APB-like agonists; the second or acute desensitizing class is represented by camphor and 1,8-cineol; and the third category represented by marked tachyphylaxis, includes menthol and dihydrocarveol. While the molecular basis of theses differences remain unknown, the finding itself points to important biophysical and pharmacological aspects of TRPV3 activity, which is modulated by different classes of chemical ligands.

Structural rearrangements of ion channels as a result of persistent agonist stimulation are emerging as a new regulatory mechanism that controls channel gating and ion conductance. Chung and colleagues (11) have demonstrated that TRPV3 shows time-dependent changes in its conduction. A recent study involving TRPV1 (57) provides similar evidence for intrinsic structural rearrangements as a result of prolonged treatment with different agonists. It is tempting to speculate whether desensitization of TRPV3 by long-term exposition of monoterpenoids is caused by similar pattern of structural rearrangements. However, the molecular dynamics of such rearrangements are not known even for TRPV1.

\section{CONCLUSION}

Monoterpenoids strongly activate and differentially desensitize TRPV3 ion channel. The desensitization of TRPV3 mediated currents is agonist-specific and time-dependent but independent of extracellular calcium or of the expression system. Our findings on monoterpenoid-induced desensitization of TRPV3 points towards a unique mechanism through which TRP channels could be functionally modulated by long-term application of specific agonists.

\section{ACKNOWLEDGEMENTS}

The financial support to Dr. Sherkheli M.A. by IMPRS-CB, Research Excellence School of Bochum and DAAD is highly appreciated. The authors would also like to thank Harry Bartel, Thomas Lichtleitner and Andrea Stöck for technical assistance.

\section{REFERENCES}

[1]. Patapoutian A., Peier A.M., Story G.M. and Viswanath V. Thermo-trp channels and beyond: Mechanisms of temperature sensation. Nature Reviews Neuroscience, 4:529-539, 2003.

[2]. Smith G.D., Gunthorpe J., Kelsell R.E., Hayes P.D, Reilly P, Facer P, Wright J.E, Jerman J.C., Walhin J.P., Ooi L, Egerton J, Charles K.J., D. Smart, Randall A. D., Anand P. and Davis J. B. TRPV3 is a temperature-sensitive vanilloid receptor-like protein. Nature, 418:186-190, 2002.

[3]. Moqrich A., Hwang S. W., Earley T. J., Petrus M. J., Murray A. N., Spencer K. S. R., Andahazy M., Story G. M. and Patapoutian A. Impaired thermosensation in mice lacking TRPV3, a heat and camphor sensor in the skin. Science, 307:1468-1472, 2005.

[4]. Peier A. M., Reeve A. J., Andersson D. A., Moqrich A., Earley T. J., Hergarden A. C., Story G. M., Colley S., Hogenesch J. B., McIntyre P., Bevan S. and Patapoutian A. A heat-sensitive TRP channel expressed in keratinocytes. Science, 296:2046-2049, 2002. 
[5]. Xu H. X., Ramsey I. S., Kotecha S. A., Moran M. M., Chong J. H. A., Lawson D., Ge P., Lilly J., Silos-Santiago I., Xie Y., DiStefano P. S., Curtis R. and Clapham D. E. TRPV3 is a calcium-permeable temperature-sensitive cation channel. Nature, 418: 181-186, 2002.

[6]. Xu H. X., Delling M., Jun J. C. and Clapham D. E. Oregano, thyme and clove-derived flavors and skin sensitizers activate specific TRP channels. Nature Neuroscience, 9:628635, 2006.

[7]. Hu H. Z., Xiao R., Wang C. B., Gao N., Colton C. K., Wood J. D., and Zhu M. X. Potentiation of TRPV3 channel function by unsaturated fatty acids. Journal of Cellular Physiology, 208:201-212, 2006.

[8]. Facer P., Casula M. A., Smith G. D., Benham C. D., Chessell I. P., Bountra C., Sinisi M., Birch R. and Anand P. Differential expression of the capsaicin receptor TRPV1 and related novel receptors TRPV3, TRPV4 and TRPM8 in normal human tissues and changes in traumatic and diabetic neuropathy. $B M C$ Neurol, 7:11, 2007.

[9]. Hellwig N., Albrecht N., Harteneck C., Schultz G. and Schaefer M. Homo- and heteromeric assembly of TRPV channel subunits. Journal of Cell Science, 118:917-28, 2005.

[10]. Xu H. X., Blair N. T. and Clapham D. E. Camphor activates and strongly desensitizes the transient receptor potential vanilloid subtype 1 channel in a vanilloid-independent mechanism. Journal of Neuroscience, 25:8924-8937, 2005.

[11]. Chung M. K., Guler A. D. and Caterina M. J. Biphasic currents evoked by chemical or thermal activation of the heat-gated ion channel, TRPV3. Journal of Biological Chemistry, 280:15928-15941, 2005.

[12]. Xiao R., Tang J. S., Wang C. B., Colton C. K., Tian J. B. and Zhu M. X. Calcium plays a central role in the sensitization of TRPV3 channel to repetitive stimulations. Journal of Biological Chemistry, 283:6162-6174, 2008.

[13]. Akopian A. N., Ruparel N. B., Jeske N. A. and Hargreaves K. M. Transient receptor potential TRPA1 channel desensitization in sensory neurons is agonist dependent and regulated by TRPV1-directed internalization. Journal of Physiology-London, 583: 175-193, 2007.

[14]. Kobayashi M., Kume H., Oguma T., Makino Y., Ito Y. and Shimokata K. Mast cell tryptase causes homologous desensitization of betaadrenoceptors by $\mathrm{Ca}^{2+}$ sensitization in tracheal smooth muscle. Clin Exp Allergy, 38:135-44, 2008.

[15]. Koplas P. A., Rosenberg R. L. and Oxford G. $\mathrm{S}$. The role of calcium in the desensitization of capsaicin responses in rat dorsal root ganglion neurons. Journal of Neuroscience, 17:3525-37, 1997.

[16]. Bhave G., Zhu W., Wang H., Brasier D. J., Oxford G. S. and Gereau R. W. t. cAMPdependent protein kinase regulates desensitization of the capsaicin receptor (VR1) by direct phosphorylation. Neuron, 35:721-31, 2002.

[17]. Ohta T., Imagawa T. and Ito S. Involvement of transient receptor potential vanilloid subtype 1 in analgesic action of methylsalicylate. Mol Pharmacol, 75:307-17, 2009.

[18]. Docherty R. J., Yeats J. C., Bevan S. and Boddeke H. W. Inhibition of calcineurin inhibits the desensitization of capsaicinevoked currents in cultured dorsal root ganglion neurones from adult rats. Pflugers Arch, 431:828-37, 1996.

[19]. Jeske N. A., Patwardhan A. M., Gamper N., Price T. J., Akopian A. N. and Hargreaves K. M. Cannabinoid WIN 55,212-2 regulates TRPV1 phosphorylation in sensory neurons. Journal of Biological Chemistry, 281:3287990, 2006.

[20]. Nilius B., Mahieu F., Prenen J., Janssens A., Owsianik G., Vennekens R. and Voets T. The $\mathrm{Ca}^{2+}$-activated cation channel TRPM4 is regulated by phosphatidylinositol 4,5biphosphate. EMBO Journal, 25:467-478, 2006.

[21]. Sherkheli M. A., Gisselmann G., Vogt-Eisele Ak, Doerner J.F. and Hatt H. Menthol derivative WS-12 selectively activates transient receptor potential melastatin-8 (TRPM8) ion channels. Pak Journal of Pharmaceutical Sciences, 21:370-8, 2008.

[22]. Taniguchi J., Takeda M., Yoshitomi K. and Imai M. Pressure- and parathyroid-hormonedependent $\mathrm{Ca}^{2+}$ transport in rabbit connecting tubule: role of the stretch-activated nonselective cation channel. Journal of Membrane Biology, 140:123-32, 1994.

[23]. Ghelardini C., Galeotti N. and Mazzanti G. Local anaesthetic activity of monoterpenes and phenylpropanes of essential oils. Planta Med, 67:564-6, 2001.

[24]. Galeotti N., Cesare Mannelli L. Di, Mazzanti G., Bartolini A. and Ghelardini C. Menthol: a natural analgesic compound. Neuroscience Letters, 322:145-8, 2002.

[25]. Santosand F. A., Rao V. S. N. Antiinflammatory and antinociceptive effects of 1,8-cineole a terpenoid oxide present in many plant essential oils. Phytotherapy Research, 14: 240-244, 2000.

[26]. Vogt-Eisele A. K., Keber K., Sherkheli M. A., Vielhaber G., Panten J., Gisselmann G. and Hatt H. Monoterpenoid agonists of TRPV3. 
British Journal of Pharmacology, 151:530540, 2007.

[27]. Hautkappe M., Roizen M. F., Toledano A., Roth S., Jeffries J. A. and Ostermeier A. M. Review of the effectiveness of capsaicin for painful cutaneous disorders and neural dysfunction. Clinical Journal of Pain, 14:97106, 1998.

[28]. Chan C. L., Facer P., Davis J. B., Smith G. D., Egerton J., Bountra C., Williams N. S. and Anand P. Sensory fibres expressing capsaicin receptor TRPV1 in patients with rectal hypersensitivity and faecal urgency. Lancet, 361:385-91, 2003.

[29]. de Sousa D. P., Raphael E., Brocksom U. and Brocksom T. J. Sedative effect of monoterpene alcohols in mice: a preliminary screening. Z Naturforsch [C], 62:563-6 2007.

[30]. Umezu T., Sakata A. and Ito H. Ambulationpromoting effect of peppermint oil and identification of its active constituents. Pharmacology Biochemistry and Behavior, 69:383-390, 2001.

[31]. Moussaieff A., Rimmerman N., Bregman T., Straiker A., Felder C. C., Shoham S., Kashman Y., Huang S. M., Lee H., Shohami E., Mackie K., Caterina M. J., Walker J. M., Fride E. and Mechoulam R. Incensole acetate, an incense component, elicits psychoactivity by activating TRPV3 channels in the brain. FASEB Journal, 2008.

[32]. Macpherson L. J., Hwang S. W., Miyamoto T., Dubin A. E., Patapoutian A. and Story G. M. More than cool: Promiscuous relationships of menthol and other sensory compounds. Molecular and Cellular Neuroscience, 32:335-343, 2006.

[33]. Mandadiand S., Roufogalis B. D. ThermoTRP channels in nociceptors: Taking a lead from capsaicin receptor TRPV1. Current Neuropharmacology, 6:21-38, 2008.

[34]. Appendino G., Minassi A., Pagani A. and Ech-Chahad A. The role of natural products in the ligand deorphanization of TRP channels. Current Pharmaceutical Designs, 14:2-17, 2008.

[35]. Villmann C., Bull L. and Hollmann M. Kainate binding proteins possess functional ion channel domains. Journal of Neuroscience, 17:7634-43, 1997.

[36]. Zufall F., Hatt H. and Firestein S. Rapid application and removal of second messengers to cyclic nucleotide-gated channels from olfactory epithelium. Proc Natl Acad Sci US A, 90:9335-9, 1993.

[37]. Kang D., Kim S. H., Hwang E. M., Kwon O. S., Yang H. Y., Kim E. S., Choi T. H., Park J. Y., Hong S. G. and Han J. Expression of thermosensitive two-pore domain $\mathrm{K}^{+}$channels in human keratinocytes cell line HaCaT cells.
Experimental Dermatology, 16:1016-1022, 2007.

[38]. Reid G. ThermoTRP channels and cold sensing: what are they really up to? Pflugers Archives, 451:250-63, 2005.

[39]. Levineand J. D. and Alessandri-Haber N. TRP channels: Targets for the relief of pain. Biochimica Et Biophysica Acta-Molecular Basis of Disease, 1772:989-1003, 2007.

[40]. Cortright D. N., Krause J. E. and Broom D. C. TRP channels and pain. Biochimica Et Biophysica Acta-Molecular Basis of Disease, 1772:978-988, 2007.

[41]. Peier A. M., Reeve A. J., Andersson D. A., Moqrich A., Earley T. J., Hergarden A. C., Story G. M., Colley S., Hogenesch J. B., McIntyre P., Bevan S. and Patapoutian A. A heat-sensitive TRP channel expressed in keratinocytes. Science, 296:2046-9, 2002.

[42]. Xu H., Ramsey I. S., Kotecha S. A., Moran M. M., Chong J. A., Lawson D., Ge P., Lilly J., Silos-Santiago I., Xie Y., Distefano P. S., Curtis R. and Clapham D. E. TRPV3 is a calcium-permeable temperature-sensitive cation channel. Nature, 418:181-6, 2002.

[43]. Singhand M. and Gopinath R. Topical analgesia for chest tube removal in cardiac patients. Journal of Cardiothoracic Vascular Anesthesiology, 19:719-22, 2005.

[44]. Smith G. D., Gunthorpe M. J., Kelsell R. E., Hayes P. D., Reilly P., Facer P., Wright J. E., Jerman J. C., Walhin J. P., Ooi L., Egerton J., Charles K. J., Smart D., Randall A. D., Anand P. and Davis J. B. TRPV3 is a temperaturesensitive vanilloid receptor-like protein. Nature, 418:186-90, 2002.

[45]. Chung M. K., Lee H., Mizuno A., Suzuki M. and Caterina M. J. 2 aminoethoxydiphenyl borate activates and sensitizes the heat-gated ion channel TRPV3. Journal of Neuroscience, 24:5177-5182, 2004.

[46]. Hu H., Grandl J., Bandell M., Petrus M. and Patapoutian A. Two amino acid residues determine 2-APB sensitivity of the ion channels TRPV3 and TRPV4. Proc Natl Acad Sci U S A, 106:1626-31, 2009.

[47]. Stotz S. C., Vriens J., Martyn D., Clardy J. and Clapham D. E. Citral sensing by transient receptor potential channels in dorsal root ganglion neurons. PLoS ONE, 3:e2082, 2008.

[48]. Zurborg S., Yurgionas B., Jira J. A., Caspani O. and Heppenstall P. A. Direct activation of the ion channel TRPA1 by $\mathrm{Ca}^{2+}$. Nature Neuroscience, 10:277-279, 2007.

[49]. Doerner J. F., Gisselmann G., Hatt H. and Wetzel C. H. Transient receptor potential channel a1 is directly gated by calcium ions. Journal of Biological Chemistry, 282:1318013189, 2007. 
[50]. Ullrich N. D., Voets T., Prenen J., Vennekens R., Talavera K., Droogman G. and Nilius B. Comparison of functional properties of the $\mathrm{Ca}^{2+}$-activated cation channels TRPM4 and TRPM5 from mice. Cell Calcium, 37:267-78, 2005.

[51]. Liu B. Y., Zhang C. G. and Qin F. Functional recovery from desensitization of vanilloid receptor TRPV1 requires resynthesis of phosphatidylinositol 4,5-bisphosphate. Journal of Neuroscience, 25:4835-4843, 2005.

[52]. Nilius B., Prenen J., Janssens A., Owsianik G., Wang C., Zhu M. X. and Voets T. The selectivity filter of the cation channel TRPM4. Journal of Biological Chemistry, 280:22899906, 2005.

[53]. Abe J., Hosokawa H., Sawada Y., Matsumura $\mathrm{K}$. and Kobayashi S. $\mathrm{Ca}^{2+}$-dependent PKC activation mediates menthol-induced desensitization of transient receptor potential M8. Neuroscience Letters, 397:140-4, 2006.
[54]. Pecze L., Szabo K., Szell M., Josvay K., Kaszas K., Kusz E., Letoha T., Prorok J., Koncz I., Toth A., Kemeny L., Vizler C. and Olah Z. Human keratinocytes are vanilloid resistant. PLoS ONE, 3:e3419, 2008.

[55]. Lee Y. M., Kim Y. K., Kim K. H., Park S. J., Kim S. J. and Chung J. H. A novel role for the TRPV1 channel in UV-induced matrix metalloproteinase (MMP)-1 expression in HaCaT cells. Journal of Cell Physiology, 2009.

[56]. Neeper M. P., Liu Y., Hutchinson T. L., Wang Y., Flores C. M. and Qin N. Activation properties of heterologously expressed mammalian TRPV2: evidence for species dependence. Journal of Biological Chemistry, 282:15894-902, 2007.

[57]. Chung M.-K., Guler A. D. and Caterina M. J. TRPV1 shows dynamic ionic selectivity during agonist stimulation. Nature Neuroscience, 11:555-564, 2008. 